\title{
Feasibility and variability of six methods for the echocardiographic and Doppler determination of cardiac output
}

\author{
GIAN LUIGI NICOLOSI, ERAZEM PUNGERCIC, * EUGENIO CERVESATO, \\ DANIELA PAVAN, LIONELLO MODENA, * EUGENIO MORO, \\ VITTORIO DALL'AGLIO, DOMENICO ZANUTTINI \\ From the Servizio di Emodinamica, Ospedale Civile, Via Montereale, Pordenone, and * Servizio di \\ Cardiologia, Soave (Verona), Italy
}

SUMMARY The feasibility and the intrinsic variability of six different methods of echocardiographic and Doppler flow determination of cardiac output were analysed in 34 healthy volunteers. Four were excluded because of poor quality echocardiograms. The mean (range) age of the remaining 30 ( 12 women, 18 men) was 21 years (13-36 years). Cardiac output was calculated by six methods as a product of echocardiographically determined cross sectional area of the aorta (apical and suprasternal views), pulmonary trunk, tricuspid annulus, and mitral annulus (circular and corrected for diastolic variations), and the flow velocity integral measured by Doppler. Cardiac output ranged from 2.79 to $6.56 \mathrm{l} / \mathrm{min}(4.45(1.29) \mathrm{l} / \mathrm{min}$ ) (mean (SD)). The feasibility of the methods ranged from $87 \%$ (26 patients) for the aorta from the suprasternal notch to $100 \%$ (30 patients) for the mitral orifice corrected for diastolic variations and for the tricuspid valve. The corresponding results for all 34 individuals were $76 \%$ and $88 \%$ respectively. Three way analysis of variance was performed in the 23 healthy volunteers in whom all six methods were feasible. Interobserver and intraobserver interpretative variabilities were $6.8 \%$ and $5.9 \%$ respectively. The intrinsic variability of each single measurement of cardiac output, independently of the observer and the method used, was $25 \%$.

Provided the image was suitable for analysis echocardiographic and Doppler flow determination of cardiac output was feasible in most healthy volunteers. But there was significant intrinsic variability for each of different methods. A single value of cardiac output in an individual should be interpreted with caution.

Studies on the echocardiographic and Doppler flow determination of cardiac output mainly consider the validation of the methods against invasive measurements. ${ }^{1-17}$ At present there is little information on the feasibility of such methods in clinical settings and on the variability associated with each method. ${ }^{18-23}$ We have analysed the feasibility and the intrinsic variability of the results of six different methods of calculating cardiac output in healthy volunteers.

Requests for reprints to Dr Gian Luigi Nicolosi, Servizio di Emodinamica, Ospedale Civile, Via Montereale, 33170 Pordenone, Italy.

Accepted for publication 19 September 1987

\section{Patients and methods}

We studied 34 healthy volunteers. Four were excluded because of poor quality echocardiograms. The mean (range) age of the remaining 30 (12 women, 18 men) was 21 years (13-36 years).

Echocardiograms and pulsed Doppler recordings were made on a Honeywell Ultra-imager with a 3.5 $\mathrm{MHz}$ mechanical transducer. Doppler sampled cardiac output (CO) was calculated by six different methods as a product of echocardiographically determined cross sectional area (A) of the aorta, ${ }^{512}$ pulmonary trunk, ${ }^{4}$ mitral annulus ${ }^{12}$ and tricuspid annulus, ${ }^{11}$ and the flow velocity integral over the cardiac cycle $(\mathrm{V})$ measured by Doppler, by the formula $\mathrm{CO}=(\mathrm{A} \times \mathrm{V} \times 60) / \cos \vartheta$. For the purpose 
of the study the $\cos \vartheta$ was assumed to be 1 for all calculations. $^{21}$

We used two different methods to calculate both the aortic and the mitral flow. The aortic flow curve was recorded from the apex ${ }^{12}$ and from the suprasternal notch. ${ }^{5}$ The mitral valve flow was calculated by the circular annulus method ${ }^{12}$ and the mitral orifice method with correction for diastolic variations. ${ }^{1}$

Still frames of the cross sectional images, derived $M$ mode tracings, and Doppler velocity outputs were recorded on hard copy for three separate cardiac cycles for further analysis. The paper speed for $M$ mode tracings and Doppler velocity outputs was $50 \mathrm{~mm} / \mathrm{s}$. Beat to beat variability was not taken into account in this study and each cross sectional, $M$ mode, and Doppler measurement was the mean of the three cycles.

One investigator obtained all the echocardiographic images and Doppler recordings from resting and haemodynamically stable individuals. Established methods were used to achieve the best Doppler signal. ${ }^{1451112}$

Two observers independently and blindly made all the measurements on two occasions. Because of the design of our computer system digitising pad, we had to trace the Doppler flow curves of the three cycles on to a plastic transparency from the hard copy. The traces were digitised independently and blindly by a third observer. ${ }^{21}$ The densest part of the velocity trace was taken as the modal velocity. The computer system calculated the area under each curve to determine the mean velocity of flow for each cycle.

The aortic diameter (from inner wall to inner wall) was measured at the onset of the QRS complex from the cross sectional parasternal long axis images, immediately distal to the aortic sinuses. ${ }^{5}$ To improve the accuracy, measurements were made on the cross sectional derived $M$ mode recordings for three separate cardiac cycles. The aortic diameter, assumed to be constant throughout systole, was used to calculate the cross sectional area of the aorta. ${ }^{5}$

Doppler flow velocity of the aorta was recorded both from the apex by the method of Lewis et al, ${ }^{12}$ and from the suprasternal notch by the method of Gardin et al. ${ }^{5}$ For both methods we tried to place the sample volume immediately distal to the aortic sinuses, where the aortic diameter was measured.

The cross sectional area of the pulmonary artery, which was assumed to be constant throughout systole, was calculated from measurements of maximal systolic diameter. ${ }^{4}$ We followed the recommendations of Goldberg et al $^{24}$ and measured maximum systolic diameter for three separate cardiac cycles from the midwall points. Pulmonary flow curves were recorded by established methods. ${ }^{411}$

The cross sectional area of the mitral valve was measured by assuming that the mitral annulus was circular and of a constant cross sectional area throughout diastole, as indicated by Lewis et al..$^{12}$ For Doppler recordings the sample volume was placed ato the level of the mitral annulus as suggested by Lewiso et al. ${ }^{12}$

For the mitral flow calculation we also used the mitral orifice method with correction for diastolico variations described by Fisher et al, ${ }^{1}$ and reported elsewhere. ${ }^{21}$ Measurement of tricuspid cross sec- tional area assumed that the tricuspid annulus was $\vec{\omega}$ circular and constant throughout diastole, as described by Loeber et al. ${ }^{11}$ The Doppler sample volume? was placed just beyond the tips of the tricuspidf leaflets. ${ }^{11}$

Final results of cardiac output values are given asi the mean of the four measurements obtained by the two observers for all six methods.

STATISTICAL ANALYSIS

We analysed the results for 23 individuals in whom all six methods could be performed. We used $a_{-}$ complete $23 \times 6 \times 2$ (subjects $\times$ methods $\times \oplus$ observers) factorial model with repeated measures. ${ }^{2500}$ The factorial component of "methods" is fixed whileㅁㅇㅁ "subjects" and "observers" are random factors. In this model the variability was regarded as coming from population, methods, observers (interobservero variability), interactions of these factors, and by으. repetition of measurements (intraobserver variability). Results were analysed by three way 3 analysis of variance..$^{25}$ Unbiased estimates of all the components of variance were obtained as linearo combinations of the mean squares in the analysis of variance. ${ }^{25}$ The null hypothesis that the contribution of any component is zero was tested by the Fisher $\mathrm{F}_{0}$ test for variance. To evaluate different factors of 3 interpretative variability for each method of calculat $-\bar{\gamma}$ ing cardiac output, a two way analysis of variance was also performed on the random factors-subjects and observers. ${ }^{25}$ Variability was given as absolute values? (standard deviation of the corresponding componento of variance) and as percentage of the mean.

\section{Results}

Calculated Doppler cardiac output values ranged from 2.79 to $6.56 \mathrm{l} / \mathrm{min}$ (mean (SD) $4.45(1.29)$ $1 / \mathrm{min})$. Mean (SD) values were different for each method, ranging from $3.2(0.6) \mathrm{l} / \mathrm{min}$ for the mitrap orifice method corrected for diastolic variations to $5 \cdot 30$ (1.3) $1 / \mathrm{min}$ for the tricuspid annulus method (table 1).0 In the 30 individuals who had good quality echocardiograms the feasibility of each method wasp $97 \%$ for the aorta from the apex, $87 \%$ for the aorta from the suprasternal notch, $90 \%$ for the pulmonary 
Table 1 Cardiac output values of the six different methods

\begin{tabular}{|c|c|c|c|c|c|c|}
\hline & $\begin{array}{l}\text { Aorta } \\
\text { apex }\end{array}$ & $\begin{array}{l}\text { Aorta } \\
\text { suprasternal }\end{array}$ & $\begin{array}{l}\text { Pulmonary } \\
\text { trunk }\end{array}$ & $\begin{array}{l}\text { Mitral } \\
\text { annulus }\end{array}$ & $\begin{array}{l}\text { Tricuspid } \\
\text { annulus }\end{array}$ & $\begin{array}{l}\text { Mitral } \\
\text { corrected }\end{array}$ \\
\hline $\begin{array}{l}\text { No } \\
\text { Mean }(1 / \mathrm{min}) \\
1 \mathrm{SD}(1 / \mathrm{min})\end{array}$ & $\begin{array}{l}29 \\
4 \cdot 7 \\
1 \cdot 2\end{array}$ & $\begin{array}{l}26 \\
4 \cdot 3 \\
1 \cdot 1\end{array}$ & $\begin{array}{r}27 \\
5 \cdot 0 \\
1 \cdot 1\end{array}$ & $\begin{array}{l}29 \\
4 \cdot 3 \\
1 \cdot 2\end{array}$ & $\begin{array}{l}30 \\
5 \cdot 3 \\
1 \cdot 3\end{array}$ & $\begin{array}{l}30 \\
3 \cdot 2 \\
0.6\end{array}$ \\
\hline
\end{tabular}

trunk, $97 \%$ for the circular mitral annulus method, $100 \%$ for the mitral orifice method corrected for diastolic variations, $100 \%$ for the tricuspid valve. For the total study group of 34 individuals the corresponding results were reduced to $85 \%, 76 \%, 79 \%, 85 \%$, $88 \%$, and $88 \%$.

The interobserver and intraobserver variabilities for cardiac output were $0.305 \mathrm{l} / \mathrm{min}(6 \cdot 8 \%)$ and $0 \cdot 265$ $1 /$ min $(5.9 \%$ ) respectively (table 2$)$. Population variability was $18.3 \%$, and method variability was $16.0 \%$ (table 2). Table 2 also shows the variability caused by the interaction between methods and population $(18.9 \%)$, between observers and population $(3.4 \%)$, between observers and methods $(5 \cdot 4 \%)$, and between observers, methods, and population $(4.8 \%)$. These results show that there was variation of the methods for different individuals, for the same observer in different subjects, for observers using different methods, and for observers in combinations with methods and subjects. The total interpretative variability of the method was $9.6 \%$-that is the variability caused by observers, repetition of measurements, and the interaction between observers and population. The intrinsic variability of each single measurement of cardiac output, independently of the observer and of the method used, was $25 \%$ (total variability without population variability).

Table 2 Results of three way analysis of variance

\begin{tabular}{|c|c|c|c|}
\hline & & $1 S D(l / \min )$ & $\%$ \\
\hline $\begin{array}{l}(a) \\
(b) \\
(c) \\
(d) \\
(e) \\
(f) \\
(g) \\
(h) \\
(i) \\
\text { (j) }\end{array}$ & $\begin{array}{l}\text { Population } \\
\text { Methods } \\
\text { Interobserver } \\
\text { Methods/population } \\
\text { Observer/population } \\
\text { Observer/methods } \\
\text { Observer/methods/population } \\
\text { Intraobserver } \\
\text { Total interpretative variability } \\
\text { Intrinsic variability of a single } \\
\text { measurement }\end{array}$ & $\begin{array}{l}0.825 \\
0.723 \\
0.305 \\
0.855 \\
0.153 \\
0.245 \\
0.216 \\
0.265 \\
0.432 \\
1 \cdot 120\end{array}$ & $\begin{array}{r}18 \cdot 3 \\
16 \cdot 0 \\
6 \cdot 8 \\
18 \cdot 9 \\
3 \cdot 4 \\
5 \cdot 4 \\
4 \cdot 8 \\
5 \cdot 9 \\
9 \cdot 6 \\
25 \cdot 0\end{array}$ \\
\hline
\end{tabular}

$d, e, f, g$, interactions between factors; $i$, total interpretative variability: variability due to observers, repetition of measurements, and the interaction between observers and population; $j$, intrinsic variability of a single measurement-total variability without variability due to the population.

All variability results are statistically significant $(p<0.01)$ (Fisher $F$ test for variance).
Table 3 shows the interpretative components of variability for each method of measuring cardiac output and table 4 shows the interpretative variability due to Doppler tracings and measurement of cross sectional area.

\section{Discussion}

We studied the feasibility of six different methods for echocardiographic and Doppler flow determination of cardiac output. Although the subjects of our study were clinically normal, image studies were unsatisfactory in four $(12 \%)$ of them. We found the same percentage in a separate different earlier series. ${ }^{21} \mathrm{We}$ also found that, provided the image was suitable for analysis, the six methods were feasible in most individuals.

We analysed the variability of interpretation of the recorded data not the variability due to the recording procedure. Interobserver and intraobserver variabilities were $6.8 \%$ and $5.9 \%$ respectively. These values are similar to those of an earlier study ${ }^{21}$ There was considerable variability $(16.0 \%)$ when different methods were used, which was close to the variability due to the population (18.3\%). Variability caused by interaction between methods and population was even higher $(18.9 \%)$, indicating that the results of the methods varied in different individuals.

It is difficult to define the factors that influence such variability. It could be that the reliability of measuring data varies in different subjects with different methods. This will make it very difficult to forecast which method will give the most reliable measurements in any one individual. Furthermore, several factors may be responsible for the discrepancies of each method.

We measured the cross sectional area of the aorta in the parasternal long axis view for both methods. For both methods we tried to place the sample volume immediately distal to the aortic sinuses, where the aortic diameter was measured. Though we tried to follow the procedure described by Gardin et al ${ }^{5}$ for measurements from the suprasternal notch, in some subjects the position of the sample volume may not have coincided with the site at which the aortic diameter was measured.

Lewis et al placed the sample volume in the middle of the left ventricular outflow tract, immediately 
Table 3 Results of two way analysis of variance for each of the six different methods of measuring cardiac output. Variability is $\vec{c}$ given as a percentage

\begin{tabular}{|c|c|c|c|c|c|c|}
\hline & $\begin{array}{l}\text { Aorta } \\
\text { apex }\end{array}$ & $\begin{array}{l}\text { Aorta } \\
\text { suprasternal }\end{array}$ & $\begin{array}{l}\text { Pulmonary } \\
\text { trunk }\end{array}$ & $\begin{array}{l}\text { Mitral } \\
\text { annulus }\end{array}$ & $\begin{array}{l}\text { Tricuspid } \\
\text { annulus }\end{array}$ & $\begin{array}{l}\text { Mitral } \\
\text { corrected }\end{array}$ \\
\hline $\begin{array}{l}\text { Interobserver } \\
\text { Intraobserver } \\
\text { Total interpretative variability }\end{array}$ & $\begin{array}{l}2 \cdot 5^{*} \\
6 \cdot 9 \\
7 \cdot 4\end{array}$ & $\begin{array}{l}4 \cdot 7^{*} \\
5 \cdot 8 \\
7 \cdot 8\end{array}$ & $\begin{array}{l}5 \cdot 6^{*} \\
4 \cdot 3 \\
7 \cdot 9\end{array}$ & $\begin{array}{c}16 \cdot 0^{*} \\
6 \cdot 8 \\
20 \cdot 0\end{array}$ & $\begin{array}{l}8 \cdot 6 \\
5 \cdot 5 \\
12 \cdot 0\end{array}$ & $\begin{array}{l}0 \cdot 1 \\
5 \cdot 3 \\
7 \cdot 7\end{array}$ \\
\hline
\end{tabular}

*p $<0.01$ (Fisher $\mathrm{F}$ test for variance).

Table 4 Results of two way analysis of variance attributable to the interpretation of Doppler measurements and cross sectional measurements for each of the six different methods. Variability is given as a percentage

\begin{tabular}{|c|c|c|c|c|c|c|}
\hline & $\begin{array}{l}\text { Aorta } \\
\text { apex }\end{array}$ & $\begin{array}{l}\text { Aorta } \\
\text { suprasternal }\end{array}$ & $\begin{array}{l}\text { Pulmonary } \\
\text { trunk }\end{array}$ & $\begin{array}{l}\text { Mitral } \\
\text { annulus }\end{array}$ & $\begin{array}{l}\text { Tricuspid } \\
\text { annulus }\end{array}$ & $\begin{array}{l}\text { Mitral } \\
\text { corrected }\end{array}$ \\
\hline $\begin{array}{l}\text { Doppler variability } \\
\text { Cross sectional variability }\end{array}$ & $\begin{array}{l}5 \cdot 4 \\
4 \cdot 6\end{array}$ & $\begin{array}{l}7 \cdot 3 t \\
4 \cdot 6\end{array}$ & $\begin{array}{l}4 \cdot 2 \\
5 \cdot 4^{\star}\end{array}$ & $\begin{array}{c}7 \cdot 8 \\
13 \cdot 8 \dagger\end{array}$ & $\begin{array}{l}9 \cdot 2^{\star} \\
7 \cdot 2\end{array}$ & $\begin{array}{c}10 \cdot 0^{\star} \\
7 \cdot 9\end{array}$ \\
\hline
\end{tabular}

${ }^{\star} p<0.05 ; \uparrow p<0.01$ (Fisher F test for variance for differences between Doppler and cross sectional variabilities).

proximal to the leaflet of the aortic valve. ${ }^{12}$ They calculated the area of the aortic annulus from the annular diameter measured immediately proximal to the points of insertion of the aortic leaflets from the parasternal long axis plane. ${ }^{12}$ We modified this approach to increase the success rate with all six methods. Though we tried to optimise the Doppler signals, it may be that in some cases we did not achieve alignment with the aortic flow above the aortic sinuses from the apex.

The fact that we measured the aortic diameter from the left sternal edge and velocities from the apex and from the suprasternal notch may also have caused difficulties.

We used the method of Goldberg et al to measure the diameter of the pulmonary artery from the midwall points, because of parallel resolution ${ }^{24}$; others prefer to measure the inner diameter. ${ }^{4}$

In calculating the mitral and tricuspid orifices ${ }^{1211}$ we assumed that they were circular with a constant cross sectional area throughout diastole. This may not be true of both valves.

The mitral orifice method, described by Fisher $e t$ $a l,{ }^{1}$ implies a correction for diastolic variation, but it seems to give lower values than the other methods (table 1).

We tried to get consistently good quality recordings to avoid one source of variability. We previously observed that the quality of the echocardiograms does not increase variability to an important extent, provided the image is suitable for analysis. ${ }^{21}$ Furthermore, the influence of the observer was within clinically acceptable limits (table 2 ). Further selection of images and tracing may reduce the feasibility of each method to unacceptable levels in clinical practice.
The intrinsic variability of a single given value of cardiac output independent of the observer and method used was $\pm 25 \%$. The mitral and the tricuspid annulus methods gave the greatest variability (table 3). This is consistent with reported data. ${ }^{20}$ Whether or not similar reproducibility would be obtained in low or high output states (that is outside the range of values considered in this study) or by using more than three beats for all calculations has yet to be determined. In this paper we examined the suggestion that variability within and between interpreters and between different methods can significantly influence the accuracy of the measurements. ${ }^{19202627}$ We found that in a small group of normal individuals the interobserver and intraobserver variability of analysing the echocardiographic and Doppler measurements required for cardiac output calculations was within clinically acceptable limits. We also found that the echocardiographic and Doppler flow determination of cardiac output was feasible in most healthy volunteers, provided that the image was suitable for analysis.

Nevertheless, the intrinsic variability of different methods was significant and a single value for an o) individual cannot be entirely reliable.

\section{References}

1 Fisher DC, Sahn DJ, Friedman MJ, et al. The mitral $\mathscr{乛}$ valve orifice method for noninvasive two-dimensional echo Doppler determinations of cardiac output. Circulation 1983;67:872-7.

2 Valdes-Cruz LM, Horowitz S, Mesel E, et al. A pulsed Doppler echocardiographic method for calculation of pulmonary and systemic flow: accuracy in a canine model with ventricular septal defect. Circulation 
1983;68:597-60'2.

3 Kitabatake A, Inoue $M$, Asao $M$, et al. Noninvasive evaluation of the ratio of pulmonary to systemic flow in atrial septal defect by duplex Doppler echocardiography. Circulation 1984;69:73-9.

4 Valdes-Cruz LM, Horowitz S, Mesel E, Sahn DJ, Fisher DC, Larson D. A pulsed Doppler echocardiographic method for calculating pulmonary and systemic blood flow in atrial level shunts: validation studies in animals and initial human experience. Circulation 1984;69:80-6.

5 Gardin JM, Tobis JM, Dabestani A, et al. Superiority of two-dimensional measurement of aortic vessel diameter in Doppler echocardiographic estimates of left ventricular stroke volume. J Am Coll Cardiol 1985;6:66-74.

6 Stewart WJ, Jiang L, Mich R, Pandian N, Guerrero JL, Weyman AE. Variable effects of changes in flow rate through the aortic, pulmonary and mitral valves on valve area and flow velocity: impact on quantitative Doppler flow calculations. J Am Coll Cardiol 1985;6:653-62.

7 Fisher DC, Sahn DJ, Friedman MJ, et al. The effect of variations on pulsed Doppler sampling site on calculation of cardiac output: an experimental study in open-chest dogs. Circulation 1983;67:370-6.

8 Ihlen $\mathrm{H}$, Amlie JP, Dale J, et al. Determination of cardiac output by Doppler echocardiography. $B r$ Heart $J$ 1984;51:54-60.

9 Huntsman LL, Stewart DK, Barnes SR, Franklin SB, Colocousis JS, Hessel EA. Noninvasive Doppler determination of cardiac output in man. Clinical validation. Circulation 1983;67:593-602.

10 Loeppky JA, Hoekenga DE, Greene ER, Luft UC. Comparison of noninvasive pulsed Doppler and Fick measurements of stroke volume in cardiac patients. Am Heart J 1984;107:339-46.

11 Loeber CP, Goldberg SJ, Allen HD. Doppler echocardiographic comparison of flows distal to the four cardiac valves. J Am Coll Cardiol 1984;4:268-72.

12 Lewis JF, Kuo LC, Nelson JG, Limacher MC, Quinones MA. Pulsed Doppler echocardiographic determination of stroke volume and cardiac output: clinical validation of two new methods using the apical window. Circulation 1984;70:425-31.

13 Nishimura RA, Callahan MJ, Schaff HV, Ilstrup DM, Miller FA, Tajik AJ. Noninvasive measurement of cardiac output by continuous-wave Doppler echocardiography: initial experience and review of the literature. Mayo Clin Proc 1984;59:484-9.

14 Rose JS, Nanna M, Rahimtoola SH, Elkayam U, McKay C, Chandraratna PAN. Accuracy of determination of changes in cardiac output by transcutaneous continuous-wave Doppler computer. Am J Cardiol 1984;54:1099-101.

15 Barron JV, Sahn DJ, Valdes-Cruz LM, et al. Clinical utility of two-dimensional Doppler echocardiographic techniques for estimating pulmonary to systemic blood flow ratios in children with left to right shunting atrial septal defect, ventricular septal defect or patent ductus arteriosus.' $\mathrm{J}$ Am Coll Cardiol 1984;3:169-78.

16 Meijboom EJ, Valdes-Cruz LM, Horowitz S, et al. A two-dimensional Doppler echocardiographic method for calculation of pulmonary and systemic blood flow in a canine model with a variable-sized left-to-right extracardiac shunt. Circulation 1983;68:437-45.

17 Distante A, Moscarelli E, Rovai D, L'Abbate A. Monitoring changes in cardiac output by transcutaneous aortovelography. A non-invasive Doppler technique: comparison with thermodilution. $J$ Nucl Med Allied Sci 1980;24:171-5.

18 Gardin JM, Dabestani A, Matin K, Allfie A, Russell D, Henry WL. Reproducibility of Doppler aortic blood flow measurements: studies on intraobserver, interobserver and day-to-day variability in normal subjects. Am J Cardiol 1984;54:1092-8.

19 Sahn DJ. Determination of cardiac output by echocardiographic Doppler methods: relative accuracy of various sites for measurement. J Am Coll Cardiol 1985;6:663-4.

20 Wallerson DC, Devereux RB. Reproducibility of quantitative echocardiography: factors affecting variability of imaging and Doppler measurements. Echocardiography 1986;3:219-35.

21 Nicolosi GL, Pungercic E, Cervesato E, Modena L, Zanuttini D. Analysis of interobserver and intraobserver variation of interpretation of the echocardiographic and Doppler flow determination of cardiac output by the mitral orifice method. Br Heart $J$ 1986;55:446-8.

22 Rein AJJT, Hsieh KS, Elixson M, et al. Cardiac output estimates in the pediatric intensive care unit using a continuous-wave Doppler computer: validation and limitations of the technique. Am Heart J 1986;112:97-103.

23 McLennan FM, Haites NE, Mackenzie JD, Daniel MK, Rawles JM. Reproducibility of linear cardiac output measurement by Doppler ultrasound alone. Br Heart J 1986;55:25-31.

24 Goldberg SJ, Allen HD, Marx GR, Flinn CJ. Flow computation. In: Doppler echocardiography. Philadelphia: Lea and Febiger, 1985:68-91.

25 Snedecor GW, Cochran WG. Statistical methods. 6th ed. Ames, Iowa: The Iowa State University Press, 1967:339-77.

26 Felner JM, Blumenstein BA, Schlant RC, et al. Sources of variability in echocardiographic measurements. Am J Cardiol 1980;45:995-1004.

27 Schuster AH, Nanda NC. Doppler echocardiographic measurement of cardiac output: comparison with a non-golden standard. Am J Cardiol 1984;53:257-9. 